\title{
Potassium channel activation inhibits proliferation of breast cancer cells by activating a senescence program
}

\author{
K Lansu ${ }^{1}$ and S Gentile ${ }^{\star 1}$
}

Traditionally the hERG1 potassium channel has been known to have a fundamental role in membrane excitability of several mammalian cells including cardiac myocytes. hERG1 has recently been found to be expressed in non-excitable cancer cells of different histogenesis, but the role of this channel in cancer biology is unknown. Results form recent studies on the effect hERG1 inhibition in some breast cancer cells are controversial as it can lead to apoptosis or protect against cell death. Nevertheless, these data suggest that the hERG1 channel could have an important role in cancer biology. Here we report the effects of hyperstimulation of hERG1 channel in human mammary gland adenocarcinoma-derived cells. Application of the hERG1 activator, the diphenylurea derivative NS1643, inhibits cell proliferation irreversibly. This event is accompanied by a preferential arrest of the cell cycle in G0/G1 phase without the occurrence of apoptotic events. Consequently, cells responded to NS1643 by developing a senescence-like phenotype associated with increased protein levels of the tumor suppressors $\mathrm{p} 21$ and $\mathrm{p} 16^{\mathrm{INK} 4 \mathrm{a}}$ and by a positive $\beta$-galactosidase assay. These data suggest that prolonged stimulation of the hERG1 potassium channel may activate a senescence program and offers a compelling opportunity to develop a potential antiproliferative cancer therapy.

Cell Death and Disease (2013) 4, e652; doi:10.1038/cddis.2013.174; published online 6 June 2013

Subject Category: Cancer

The voltage-gated hERG1 potassium channel has a fundamental role in controlling membrane excitability of cardiac myocytes and therefore heart contractility. ${ }^{1,2}$ Interestingly, hERG1 has also been found expressed in several nonexcitable neoplastic tissues. ${ }^{3-8}$ However, the role of hERG1 in these cells is still obscure.

It has also been found that hERG channel expression can change during formation of neuronal crest $^{9}$ or in muscular systems of quail embryos. ${ }^{10}$ In addition, in tumor cells, hERG1 gene expression varies during different phases of the cell cycle. ${ }^{11}$ It also has been shown that inhibition of hERG1 current activity can inhibit proliferation in leukemic cells by promoting cell cycle arrest. ${ }^{12-14}$ These data suggest that the $\mathrm{hERG} 1$ channel might have an important role in controlling the cell cycle.

In addition, hERG channel blockers can lead to apoptosis; however, this event appears to be independent of their ability to arrest the cell cycle. ${ }^{13,15}$

In contrast, it also has been reported that a $\mathrm{H}_{2} \mathrm{O}_{2}$ dependent increase of hERG1 current activity promoted caspase-3 activation in several cancer cell lines including SKBr3. ${ }^{15}$ This effect was inhibited by the hERG1 blocker dofetilide. ${ }^{15}$

Despite these seemingly contradictory observations, the findings suggest that hERG1 might have an important role in non-excitable cells and raise the possibility that a function for
hERG1 in promoting or protecting from apoptosis might coexist according to the biological condition.

Unfortunately, hERG1 potassium channel antagonists are strongly associated with cardiac arrhythmias: acquired long QT (aLQT2) and cardiac ventricular fibrillation; these potentially fatal events limit the use of hERG1 blockers for anticancer therapy.

On the other hand, current research in pharmacology has identified several reversible activators of hERG1 channels, which have the ability to improve cardiac function in LQT2 animal models. ${ }^{16-22}$ Among these, the best characterized hERG1 agonist is the diphenylurea derivative NS1643. ${ }^{19,23} \mathrm{At}$ present, the effects of this drug on the biology of hERG1positive cancer cells remain unexplored.

The present study was carried out to investigate the effect of the hERG1 channel activator on human mammary gland adenocarcinoma. ${ }^{8,15}$ The specific type of cell lines that we used, SKBr3 and MDA-MB-231 lack expression of: estrogen $\alpha$ and/or $\beta$-type receptors (ERneg) and progesterone receptor. In addition, SKBr3 cells present a high expression level of the human epidermal growth factor receptor 2 (ErbB-2). This cancer phenotype is associated with a high mortality rate.

To gain insights into the mechanism of action of NS1643, we examined several biological parameters including proliferation rate, cell cycle phase distribution, expression level of several cell cycle biomarkers, apoptosis and senescence.

\footnotetext{
${ }^{1}$ Molecular Pharmacology and Therapeutics, Loyola University, Chicago, IL, USA

*Corresponding author: S Gentile, Molecular Pharmacology and Therapeutics, Loyola University, Chicago, IL, USA. Tel: +708 2163263 ; Fax: +708 216 6596. E-mail: sagentile@lumc.edu

Keywords: hERG1; potassium channel; senescence; cancer; proliferation

Abbreviations: hERG1, human ether-a-go-go related gene 1; aLQT2, acquired long QT; ErbB-2, human epidermal growth factor receptor 2; NS1643, N,N'-Bis[2hydroxy-5-(trifluoromethyl) phenyl] urea; PD118057, 2-[[4-[2-(3,4-Dichlorophenyl) ethyl] phenyl] amino] benzoic acid; p16 ${ }^{\text {INK4A }}$, multiple tumor suppressor 1

Received 31.1.13; revised 21.4.13; accepted 22.4.13; Edited by A Stephanou
} 
We report here for the first time that exposing human mammary gland adenocarcinoma to the hERG1 channel activator NS1643 leads to arrest of the cell cycle in G0/G1 phase by activating a senescence program. Although the biological meaning of senescence is still poorly understood, several studies have revealed that this stable form of cell cycle arrest can have a fundamental role in tumor suppression. This work provides the first evidence for a role of hERG1 potassium channel in promoting cellular senescence in breast cancer. Furthermore, it offers an opportunity to design an antiproliferative pharmacological strategy for cancer cells expressing hERG1 channel.

\section{Results}

hERG1 agonists cause irreversible inhibition of cell proliferation in human mammary gland adenocarcinomaderived cells. To characterize the effects of the hERG1 channel agonists on breast cancer cells, we first identified two cell lines that were expressing hERG1 channel. We found that human mammary gland adenocarcinoma-derived SKBr3 (Figures 1a and b) or MDA-MB-231 (Supplementary
Figure 1A) cells express functional hERG1 channel. Then we investigated the consequences of hERG1 current activity stimulation on proliferation of dividing cells by exposing both cell lines to increasing concentrations of NS1643 (0-10-25$50 \mu \mathrm{m})$. Proliferation rate was measured by counting cells at 24-48-72 h. We found that application of NS1643 caused a significant inhibition of cell proliferation in both cell lines (Figure1c; Supplementary Figure 1B).

Unfortunately, our attempts to manipulate expression level of the hERG1 channel by using siRNA ${ }^{24}$ did not provide viable cells as they died within $24 \mathrm{~h}$ after transfection. However, to gain insight on the selectivity of NS1643, we repeated measurements of proliferation rates with Chinese Ovary Hamster Ovary cells (CHO-H1, ATCC), which do not express hERG1 (Figure 1d). We observed that in these cells proliferation rate was unaltered at any concentration of NS1643 and at any time point (Figure 1f).

To gain more insight on the specificity of the hERG1 channel in determining inhibition of cell proliferation we also exposed cells to an alternative hERG1 agonist PD118057. This drug is structurally different from NS1643 (Supplementary Figures $1 \mathrm{~A}$ and $\mathrm{B}$ ). We found that this drug

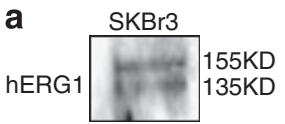

b

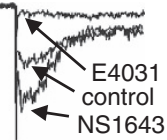

C

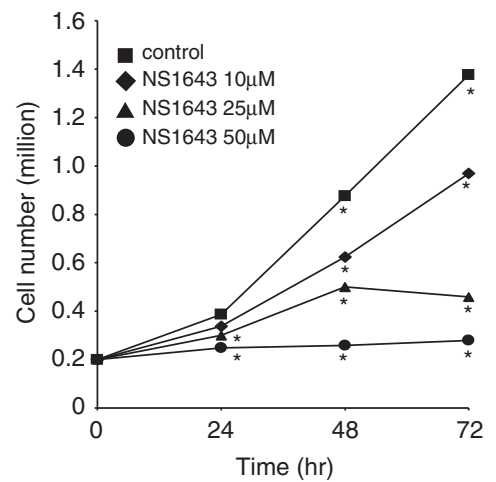

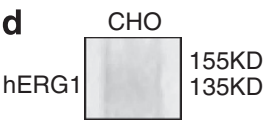

e
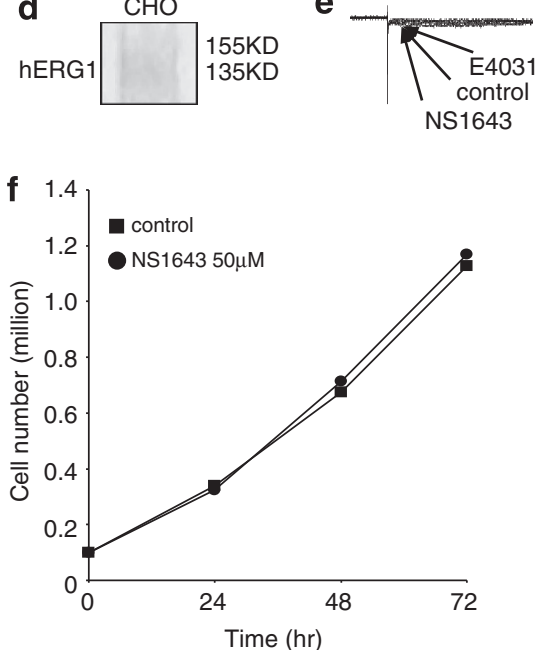

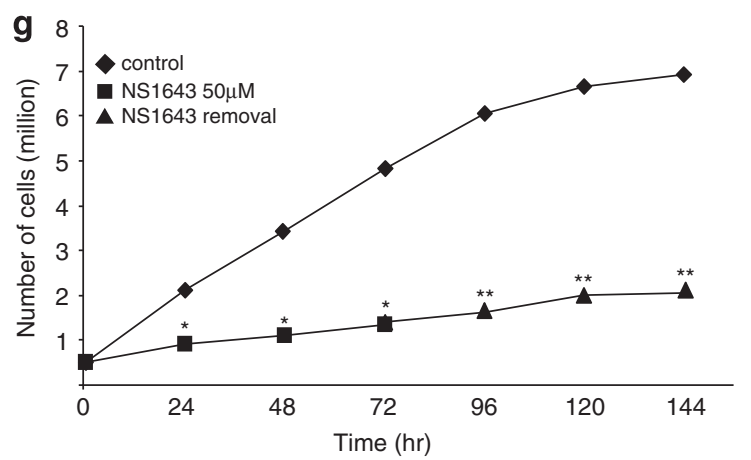

Figure 1 (a) Western blot indicating positive expression of hERG1 channel in SKBr3 cells. (b) Effect of NS1643 (50 $\mu \mathrm{m})$ on hERG1 current detected in SKBr3 cells $48 \mathrm{~h}$ after drug treatment compared with untreated cells (control). hERG1 current specificity was confirmed by application of the selective hERG1 blocker E4031 (5 $\mu \mathrm{M})$. (c) Effect of NS1643 on SKBr3 cell proliferation rate at different time points $\left(n=6 ;{ }^{*} P<0.01\right)$. (d) Western blot indicating negative expression of $h E R G 1$ channel in $\mathrm{CHO}$ cells. (e) Effect of NS1643 $(50 \mu \mathrm{M})$ or E4031 $(5 \mu \mathrm{M})$ on hERG1 current detected in CHO cells $48 \mathrm{~h}$ after drug treatment compared with untreated cells (control). (f) Effect of NS1643 on CHO cell proliferation rate at different time points compared with untreated cells $(n=6)$. (g) Measurements of proliferation rates of SKBr3 during NS1643 treatment (50 $\mu \mathrm{M}$; square box) and after drug removal (triangle) compared with control (diamond). $\left(n=6 ;{ }^{*} P<0.025\right)$ 
also strongly inhibited proliferation rate similarly to what was observed with NS1643.

Interestingly, inhibition of cell proliferation by the hERG1 agonist NS1643 appeared to be irreversible. The stimulating effect of NS1643 on hERG1 current has been shown to be reversible upon removal of the drug. ${ }^{19}$ To determine if the effect of NS1643 could be rescued by removal of the drug, SKBr3 cells were first treated with $50 \mu \mathrm{m}$ NS1643 for up to $72 \mathrm{~h}$ (Figure 2). To maximize the effects we decided to use a NS1643 drug concentration of $50 \mu \mathrm{m}$, which corresponds to at least twice the $\mathrm{EC}_{50}$ value to activate the hERG1 channel. ${ }^{23}$ After drug treatment, cells were washed five times with phosphate-buffered saline (PBS) solution and fresh drug-free medium was added. Washing and drug-free medium replacement was performed every $24 \mathrm{~h}$ for 3 days. Cell proliferation rate was monitored every $24 \mathrm{~h}$ for 3 days. Data were analysed and compared with untreated cells. As previously observed, NS1643 treatment strongly inhibited cell growth compared with untreated cells (Figure 1g). Moreover, this inhibition was maintained even after replacing the medium with drug-free medium (Figure 1g). These data suggest that the effect of NS1643 on breast cancer cells expressing the hERG1 channel is not rescued by removal of the drug, resulting in an irreversible outcome.

hERG1 agonist-dependent cell cycle arrest is not associated with cell death. In our experiments, the effect of hERG1 agonists on cell proliferation rate could be due to an increased cell death. Therefore, we used trypan blue staining to select and quantify dead cells in plates containing SKBr3 (Figure 2a) or $\mathrm{CHO}$ (Figure $2 \mathrm{~b}$ ) cells treated with or without NS1643. Cells that became sensitive to trypan blue staining
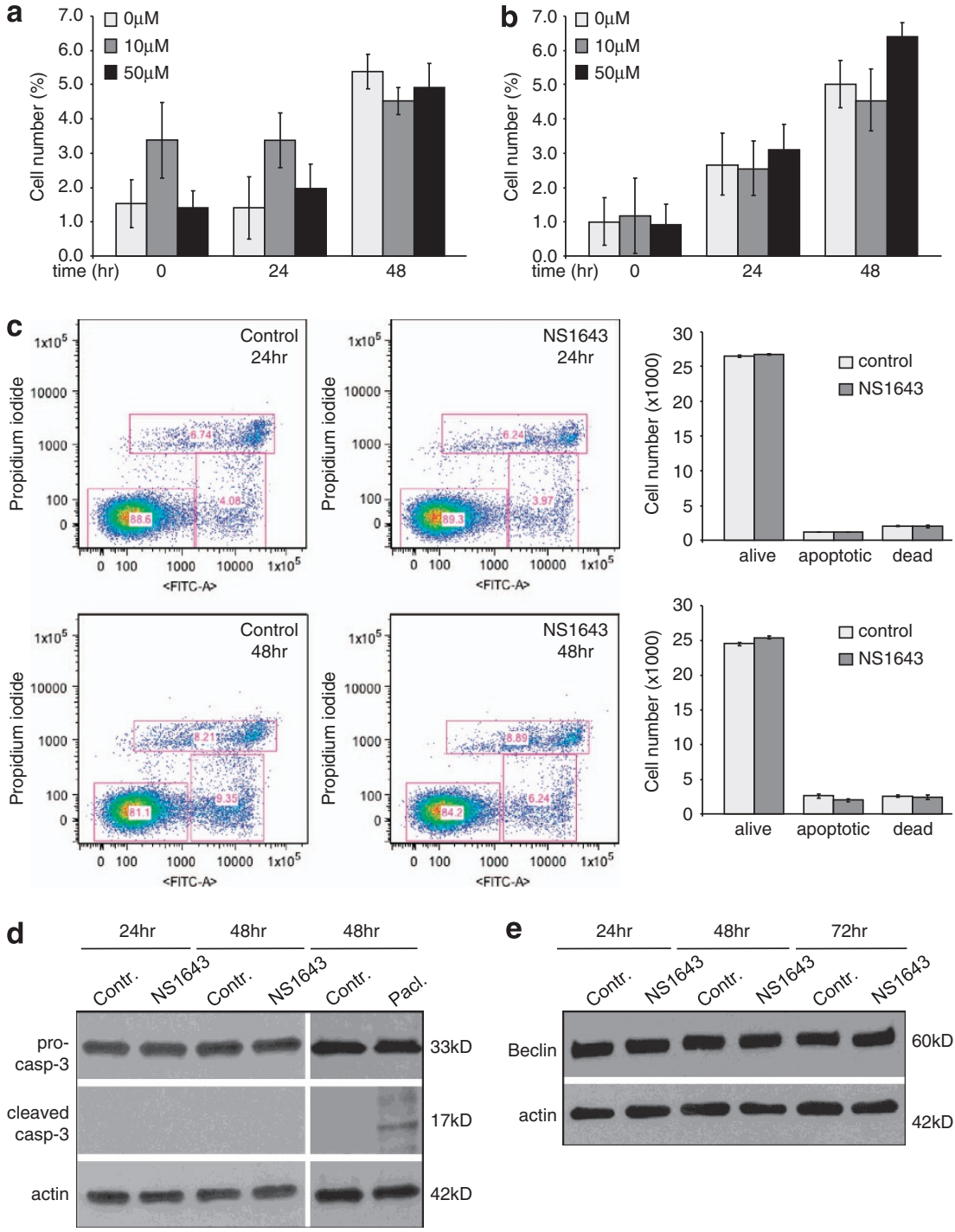

Figure 2 (a) Detection of cell death in SKBr3 cells and (b) CHO cells treated for up to $48 \mathrm{~h}$ with or without different concentrations of NS1643 $(0 \mu \mathrm{m}$ light gray bar; $10 \mu \mathrm{m}$ dark gray bar; $50 \mu \mathrm{m}$ black bar) by using trypan blue staining method. Each experiment was repeated five times. (c) AnnexinV apoptosis detection (Abcam; Cambridge, MA, USA) in SKBr3 cells before ((Control) and after 24 and $48 \mathrm{~h}$ ) treatment with $50 \mu \mathrm{m} \mathrm{NS1643.} \mathrm{(d)} \mathrm{Histograms} \mathrm{indicate} \mathrm{the} \mathrm{number} \mathrm{of} \mathrm{alive,} \mathrm{apoptotic} \mathrm{or} \mathrm{dead} \mathrm{cells} \mathrm{in} \mathrm{NS1643}$ treated (dark gray bar; $n=3$ ) or untreated (light gray bar; $n=3$ ) dishes. (d) Western blot analyses of the effect NS1643 on activation and photolytic cleavage of caspase-3 (Cell signaling Technology Inc.; cleaved-casp-3) in SKBr3 cells $(n=3)$ compared with untreated cells (Control). Effect of the caspase-3 activator paclitaxe ${ }^{25}$ in SKBr3 cells was used as positive control. (e) Western blot analyses of the effect NS1643 on the autophagy biomarker Beclin-1 (Cell signaling Technology Inc.) 
were monitored by using light microscopy or an automated cell counter (Countess, Invitrogen, Grand Island, NY, USA).

Interestingly, this method did not reveal any notable difference in the number of dead cells between treated or untreated $\mathrm{SKBr} 3$ or $\mathrm{CHO}$ cells in all samples tested (Figures $2 a$ and $b)$.

To gain more insights into a possible hERG1 agonistdriven cell death mechanism, we also monitored apoptosis by using AnnexinV-based immunofluorescence (Figures 2c and d). Subconfluent SKBr3 or MDA-MB-231 cells were exposed to $50 \mu \mathrm{m}$ NS1643 for up to $48 \mathrm{~h}$ and apoptotic events were monitored. As shown in Figures $2 \mathrm{c}$ and $\mathrm{d}$ and in Supplementary Figures $2 a$ and b, the percentage of apoptotic cells did not change upon treatment with NS1643 at any indicated time point. In addition, we also monitored caspase3 activity as it is known to be one of the major effectors in potassium channel-dependent apoptotic events. ${ }^{15}$ Western blot analyses of SKBr3 or MDA-MB-231 cells treated with NS1643 for up to $48 \mathrm{~h}$ revealed no detection of active caspase-3 or reduction of protein pro-caspase-3 density as indication of protein activation by cleavage (Figure 2e; Supplementary Figure 2C).

Alternatively, we performed western blot analyses of beclin-1, a marker of autophagy. Interestingly, we did not detect any significant changes of beclin-1 protein level after NS1643 treatment for up to $72 \mathrm{~h}$ in either cell line (Figure 2f, Supplementary Figure 2D).

In conclusion, these data indicate that the inhibitory effect of NS1643 on cell proliferation rate is not associated with an increased cell death or apoptosis.

hERG1 agonist induces cell cycle arrest in G0/G1 phase. NS1643-dependent inhibition of cell proliferation most probably implies that the drug affects progression of the cell cycle. Therefore, we analysed changes in the cell cycle with flow cytometry. Subconfluent cultures of SKBr3 or
MDA-MB-231 cells were treated with NS1643 or DMSO (control) for different time points (Figure 3; Supplementary Figure 3). Then, DNA content in cells from each plate was analysed with flow cytometry by propidium iodide staining. Treatment with $50 \mu \mathrm{m}$ NS1643 for $48 \mathrm{~h}$ caused significant changes in percent of distribution in different cell cycle phases in both cell lines as follows.

SKBr3 (Figures $3 a$, b and d): increase of cell fraction in $\mathrm{G} 1$ phase compared with untreated cells (control G0/ G1 $=38 \% \pm 7 \%$; NS1643 =69\% $\pm 7 \%$; ; decrease of the cell fraction in S phase (control S=53\% $\pm 3 \%$; NS1643 $\mathrm{S}=24 \% \pm 3 \%$ ) and a significant decrease of percent of cell fraction in G2/M phase (control G2/M $=22 \% \pm 6 \%$; NS1643 $\mathrm{G} 2 / \mathrm{M}=6 \% \pm 2)$.

MDA-MB-231: increase of cell fraction in $\mathrm{G} 1$ phase compared with untreated cells (control G0/G1 $=45 \% \pm 8 \%$; $\mathrm{NS} 1643=56 \% \pm 7 \%$ ); decrease of the cell fraction in S phase (control $S=40 \% \pm 3 \%$; NS1643 $S=32 \% \pm 4 \%$ ) and a significant decrease of percent of cell fraction in G2/M phase (control G2/M = 15\% $\pm 3 \%$; NS1643 G2/M = 3\% \pm 2 ).

Interestingly, application of the selective hERG1 blocker E4031 in combination with NS1643 rescued the effect of NS1643 alone (Figure 3c; G0/G1 = 52\% $\pm 4 \%$; S = 28\% $\pm 6 \%$; $\mathrm{G} 2 / \mathrm{M}=5 \% \pm 2 \%$ ) confirming the specificity of hERG1 channel in determining its agonist-dependent inhibition of cell proliferation.

In conclusion, these data suggest that stimulation of hERG1 activity can lead to preferential arrest of the cell cycle in G0/G1 phase.

hERG1 agonist decreased expression level of proteins promoting $\mathrm{G1}-\mathrm{S}$ transition, $\mathrm{S}$ phase and $M$ phase. As NS1643 caused preferential cell cycle arrest in G0/G1 phase and reduced the fraction of cells in the $S$ phase and $M$ phase, we examined the effect of this drug on the expression level of biomarkers for different cell cycle phases.
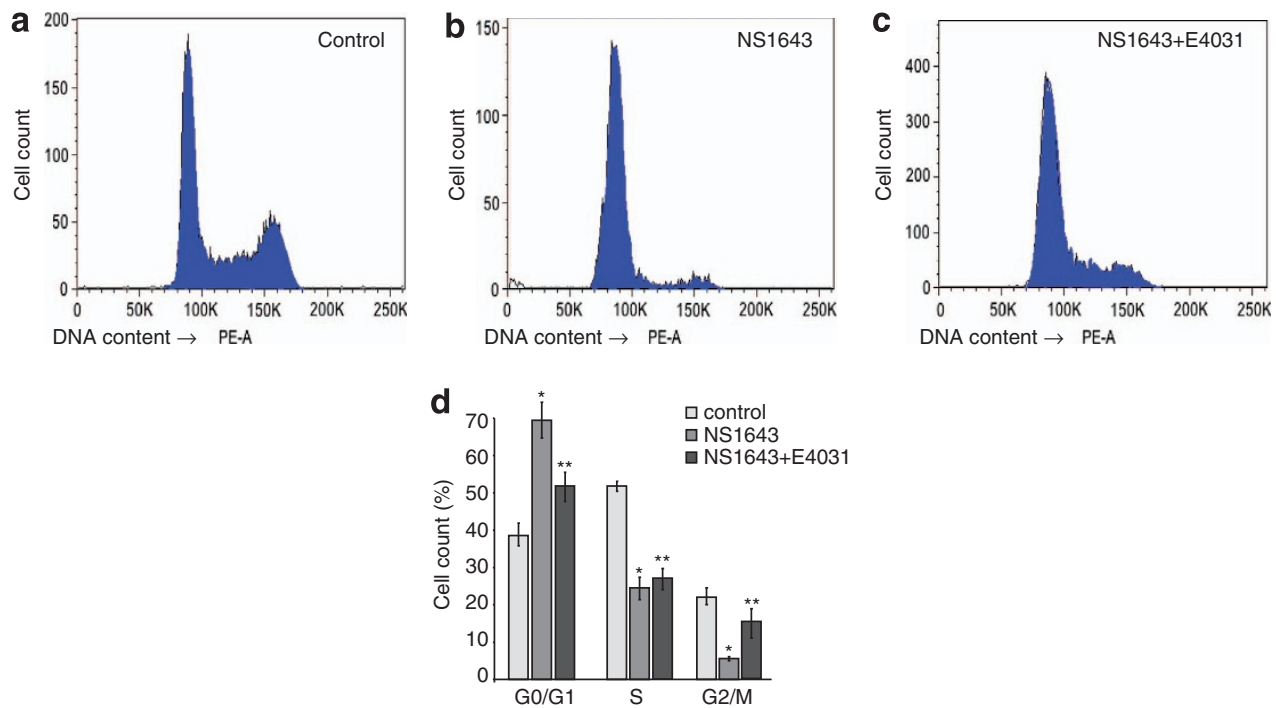

Figure 3 (a-c) Flow cytometry analyses of DNA content of SKBr3 cells treated for $48 \mathrm{~h}$ with DMSO (control), NS1643 (50 $\mu \mathrm{m})$ or NS1643 (50 $\mu \mathrm{m})$ in combination with the selective hERG1 channel blocker E4031 (5 $\mu \mathrm{m})$ cells. (d) Histograms showing the percentages of cells at various phases of cell cycle in untreated cells (light gray bar; $n=3$ ), NS1643-treated cells (dark gray bars; $n=3$ ) or treated with NS1643 + E4031 (black bars). * indicate a statistically significant difference from untreated control. $P<0.005$.

${ }^{* *}$ indicate a statistically significant difference from NS1643 treatment alone. $P<0.005$ 
To investigate the effect of NS1643 on proteins playing a major role in controlling $\mathrm{G} 1$ to $\mathrm{S}$ transition we performed a series of time course western blot analyses detecting expression level of cycline $\mathrm{E} 2$, retinoblastoma $(\mathrm{Rb})$ and cyclin-dependent kinase 1 (Cdk1) before and after application of $50 \mu \mathrm{m}$ NS1643. As shown in Figure 4a, application of NS1643 resulted in a decrease of cyclin E2 at the earliest time point of $2 \mathrm{~h}$. After $24 \mathrm{~h}-\lambda$ treatment, cyclin E2 completely disappeared. Monitoring $\mathrm{Rb}$ protein expression upon cell treatment with NS1643 also revealed a decrease in this protein's levels but only after treatments longer than $24 \mathrm{~h}$ (Figure 4a). In addition, protein levels of Cdk1 significantly decreased $24 \mathrm{~h}$ after treatment with NS1643.

As the effect of NS1643 on cell cycle was associated with a reduction of the fraction of cells in $S$ phase, we monitored protein levels of cyclin A2, the activity of which is required for progression through the $S$ phase in dividing somatic cells. ${ }^{26}$ Application of NS1643 did not affect the expression level of cyclin $\mathrm{A} 2$ after $2 \mathrm{~h}$ treatment (Figure $5 \mathrm{a}$ ) (as was seen for cyclin E2 (Figure 4a)); however, cyclin A2 protein significantly decreased after $24 \mathrm{~h}$ and completely disappeared after $36 \mathrm{~h}$ (data not shown).

In addition, we also monitored Wee1, as its activity is important for traversing the G2/M checkpoint and $\mathrm{pH} 3$, which is thought to have a major role in promoting mitosis. ${ }^{27,28}$ As shown in Figures $5 \mathrm{~b}$ and c, western blot analyses of cells treated with NS1643 revealed no significant change of protein expression after $2 \mathrm{~h}$ of drug treatment. Nevertheless, a strong reduction of both proteins' expression level was detected after $24 \mathrm{~h}$ of drug treatment.

Altogether, these results suggest that the hERG1 agonist NS1643 inhibits proliferation of SKBr3 cells by downregulating the expression of a plethora of important cell cycle phasespecific biomarkers including an early decrease of cyclin E2.

hERG1 agonist treatment increases protein level of cellular senescence markers. The effect of the hERG1 agonists on breast cancer cells can be summarized as follows: a decrease in proliferation rate caused by an irreversible arrest of the cell cycle in G1 phase, and absence of apoptotic events. Altogether, these findings support the hypothesis that NS1643 treatment might lead to a loss of the cancerogenic behavior. To further test this hypothesis we monitored the protein expression level of negative regulators of the cell cycle such as the anti-apoptotic and tumor suppressor p21 and the multiple tumor suppressor and senescence program activator $\mathrm{p} 16^{\mathrm{INK} 4 \mathrm{a}}$.

Western blot analyses of SKBr3 or MDA-MB-231 cells treated with NS1643 revealed a significant increase in the level of p21 protein already after $24 \mathrm{~h}$ treatment with NS1643 compared with untreated cells (Figure 6a; Supplementary Figure 4A). Earlier detection did not reveal significant changes in p21 expression. Irreversible cell cycle arrest can be indicative of activation of a cell senescence program; we therefore measured expression level of $\mathrm{p} 16^{\mathrm{INK} 4 \mathrm{a}}$ and $\beta$-galactosidase activity as hallmarks for senescence. ${ }^{29-31}$ Cells treated with NS1643 for $24 \mathrm{~h}$ showed a small but statistically significant increase of $\mathrm{p} 16^{\mathrm{INK} 4 \mathrm{a}}$ expression, which strongly increased after $48 \mathrm{~h}$ drug treatment in both cell lines in comparison with untreated cells (Figure 6b, Supplementary Figure 4B). In addition, senescence-associated acidic $\beta$-galactosidase staining (SA- $\beta$-Gal) also displayed a strong positivity only in cells treated with NS1643 for $48 \mathrm{~h}$.
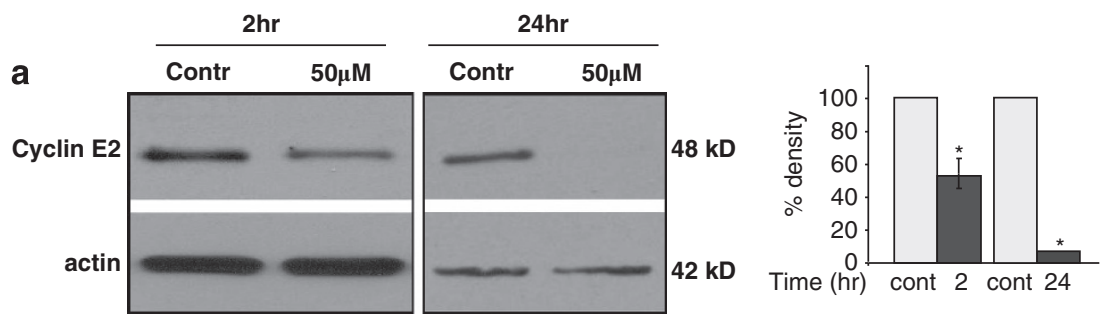

b
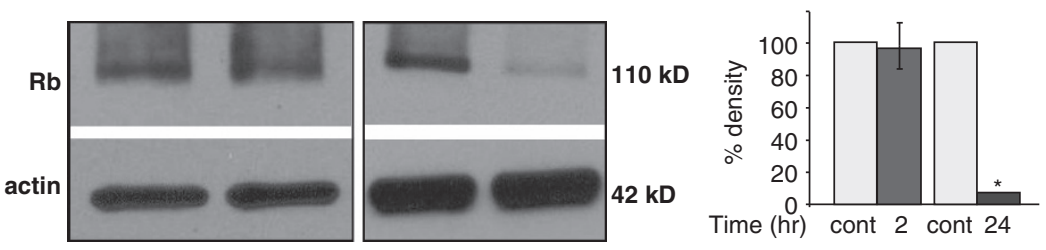

C
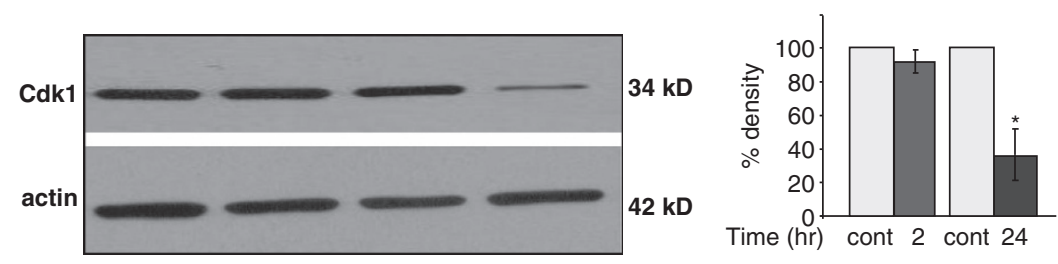

Figure 4 (a) Western blot analyses indicating the effects of NS1643 treatment on cyclin E2, (b) Rb and (c) Cdk1. Each protein expression is represented graphically (right panel) upon 2 or $24 \mathrm{~h}$ treatment with NS1643 (dark gray bars; $n=3 ;{ }^{*} P<0.05$ ) and compared with control (C2 or C24, light gray bars; $n=3$ ) or $24 \mathrm{~h}$ treatment. The chart shows the average total optical density of the specific protein band from the densitometric analysis of immunoblots expressed as percentage change of control. Data were normalized to protein expression levels present in cells with no drug added 

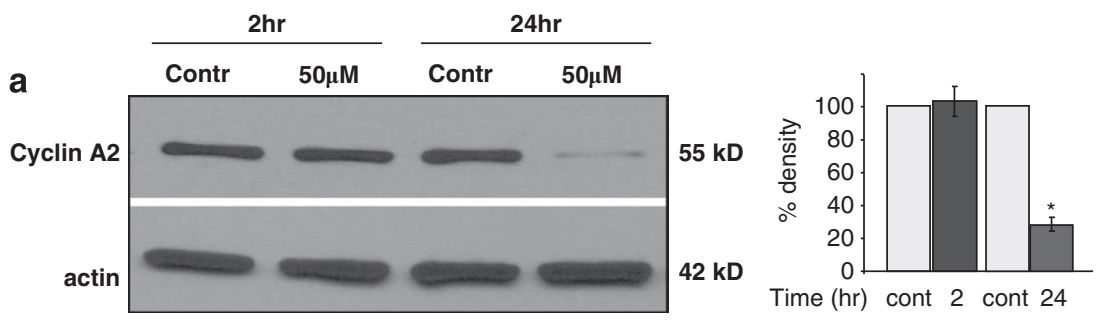

b

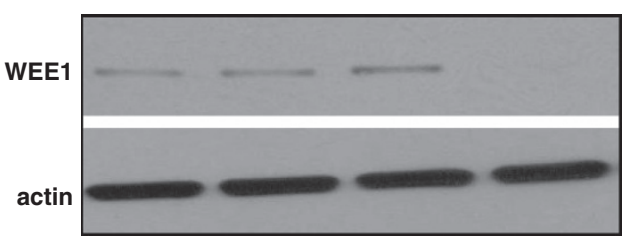

$95 \mathrm{kD}$

C
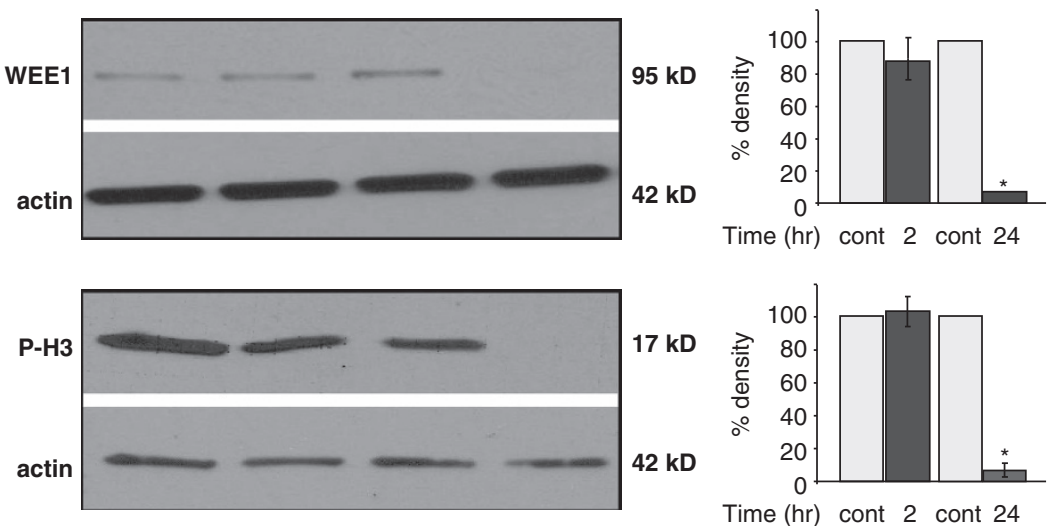

Figure 5 (a) Western blot analyses indicating the effects of NS1643 treatment on cyclin A2, (b) WEE1 and (c) phosphorylated histone-3. Each protein expression is represented graphically (right panel) upon 2 or $24 \mathrm{~h}$ treatment with NS1643 (dark gray bars; $n=3 ;{ }^{*} P<0.01$ ) and compared with control (C2 or C24, light gray bars; $n=3$ ) or $24 \mathrm{~h}$ treatment. The chart shows the average total optical density of the specific protein band from the densitometric analysis of immunoblots expressed as percentage change of control. Data were normalized to protein expression levels present in cells with no drug added. Asterisk indicates a statistically significant difference from untreated control

Altogether, this study for the first time provides evidence that prolonged stimulation of hERG1 channel leads to inhibition of proliferation in SKBr3 or MDA-MB-231 breast cancer cells. This phenomenon can be linked to a fast decrease of cyclin E2 protein level, which determines an accumulation of the cells in G0/G1 phase and an increase of tumor suppressor proteins and markers for cellular senescence including $\mathrm{p} 21, \mathrm{p} 16^{\mathrm{INK} 4 \mathrm{a}}$ and $\beta$-galactosidase activity. Therefore, we suggest that the effects of hERG1 agonists might have a role in determining cell cycle arrest by activating a cellular senescence program.

\section{Discussion}

Potassium channel activity have a fundamental role in maintaining cellular homeostasis or induction of cell death. ${ }^{32-36}$ As a rule of thumb, an increase of potassium channel activity leads to membrane hyperpolarization while a decrease in activity leads to depolarization. By determining variations of membrane potential, they can activate and coordinate many cellular events including neuronal transmission, muscle contraction and exocrine or endocrine secretion. $^{34}$

It has been found that proliferating cells undergo changes of membrane potential during progression of the cell cycle. ${ }^{37}$ In addition, cancer cells have a more depolarized membrane potential compared with quiescent cells. ${ }^{38}$ This raises the possibility that potassium channels may also have a fundamental role in cell proliferation.

Interestingly, the level of mRNA encoding for the hERG1 potassium channel have been found to change throughout the cell cycle, reaching their highest level in G0/G1 phase. ${ }^{11}$ It has also been shown that constitutive inhibition of the hERG1 channel activity can induce cell cycle arrest in G0/G1 phase in several cancer cells. ${ }^{12}$

Surprisingly, results from the present study demonstrate that prolonged stimulation of hERG1 channel in the ERnegative breast cancer SKBr3 cells treated with NS1643 arrested the cells in the G0/G1 phase. Altogether, these data suggest that hERG1 channel activity is essential for the G1 to $S$ transition. However, this cellular event might take place only when hERG1 channel activity can oscillate or be maintained in a specific range as both hyperstimulation (shown here) and constitutive inhibition of the channel leads to cell cycle arrest in $\mathrm{G} 0 / \mathrm{G} 1$. $^{15}$

Cyclin E2 is one of the most important proteins that mediate the $\mathrm{G} 1$ to $\mathrm{S}$ transition of the cell cycle. ${ }^{39,40}$ This protein determines phosphorylation of $\mathrm{Rb}$ by activating its catalytic partner, Cdk1. Hyperphosphorylation of $\mathrm{Rb}$ disrupts its association with transcription factors, altering the pattern of gene expression and permitting cell proliferation and/or apoptosis.

As of the importance that cyclin E2 has in regulating the cell cycle, it is our opinion that one of the most significant effects of stimulating hERG1 channel in ERneg breast cancer cells is the related to a decreased level of E2. This event appears to occur after only $2 \mathrm{~h}$ of drug treatment, whereas none of the other detected cell cycle biomarkers were affected at this early time point.

It has been demonstrated that cyclin E2 exerts its powerful influence on proliferation by controlling transcription of the cyclin $\mathrm{A} 2$ gene. ${ }^{41,42}$ Coincidentally, we found that expression 
a
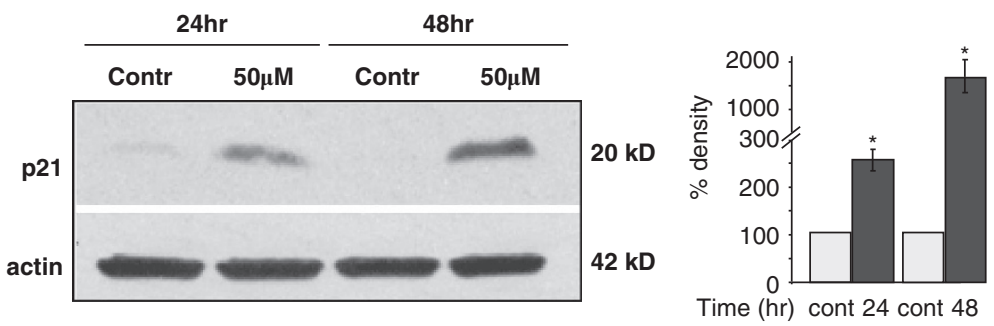

b

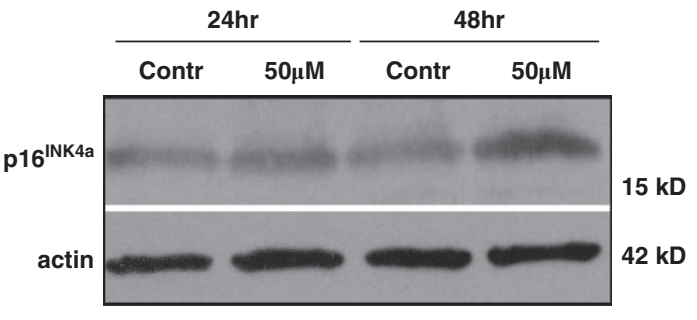

C

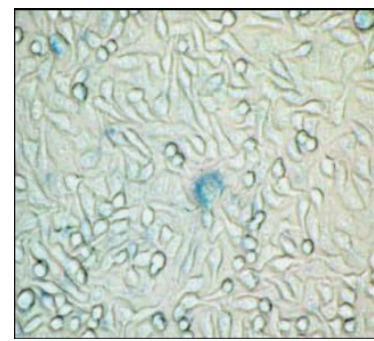

d

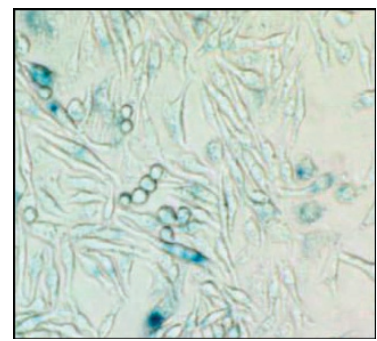

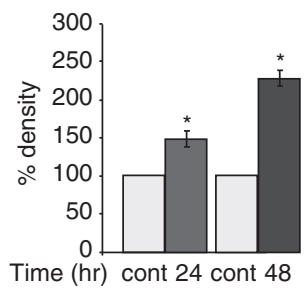

e

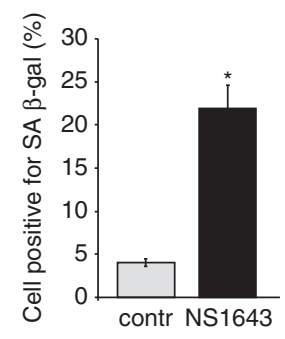

Figure 6 Western blot analyses indicating the effects of NS1643 treatment on (a) p21 and (b) p16INK4a. Each protein expression is represented graphically (right panel) upon treatment with NS1643 for $24 \mathrm{~h}$ (dark gray bars; $n=3 ;{ }^{*} P<0.001$ ), $48 \mathrm{~h}$ (black bars; $n=3$ ) compared with no treated cells (C24 or C48, light gray bars; $n=3$ ). The chart shows the average total optical density of the specific protein band from the densitometric analysis of immunoblots expressed as percentage change of control. Data were normalized to protein expression levels present in cells with no drug added. (c) Photomicrographs representing SA- $\beta$-Gal activity by visualization of blue staining of untreated SKBr3 cells and (d) SKBr3 cells treated with NS1643 for $48 \mathrm{~h}$. (e) Histograms representing the number of cells stained in blue as percent of total cells in untreated dishes (light gray bar; $(n=5)$; control) or drug treated dishes (black bar; $\left.n=5 ;{ }^{*} P<0.05\right)$. SA- $\beta$-Gal activity was quantified by counting 100 cells on three separate areas for each treatment. Asterisk indicates a statistically significant difference from untreated control

of cyclin A2 was strongly reduced only after that E2 was downregulated. It is known that cyclin A2 activity is fundamental for progression of the $S$ phase. ${ }^{26}$ Therefore, a decrease of this protein abundance is consistent with the flow cytometry analyses indicating a significant decrease of cell number in the S phase after treatment with NS1643.

Similarly, phosphorylation of histone-3, which controls the progression of mitosis, was strongly reduced after $24 \mathrm{~h}$ treatment. This event is indicative of an incomplete progression of the $S$ phase and depletion of a fundamental protein promoting transition from $\mathrm{G} 2$ to $\mathrm{M}$ phase.

Altogether, these data suggest that stimulation of hERG1 channels rapidly hindered the cell cycle machinery by inhibiting the activity of the early key regulatory protein cyclin E2. Interestingly, 24h treatment with NS1643 also led to downregulation of $\mathrm{Rb}$ and $\mathrm{Cdk} 1$. These events coincided with an increase of the senescent cell marker $\mathrm{p} 16^{\mathrm{INK} 4 \mathrm{a}}$ proteins level. It has been previously reported that $\mathrm{p} 16^{\mathrm{INK} 4 \mathrm{a}}$ controls $\mathrm{Rb}$ activity by inhibiting its transcription. ${ }^{43}$ Furthermore, p16 ${ }^{\text {INK4a }}$ inhibits Cdk1 expression via post-transcriptional events. ${ }^{44}$ Therefore, we can speculate that the effects of NS1643 on Rb and Cdk1 could be attributed to the increased density of $\mathrm{p} 16^{\mathrm{INK} 4 \mathrm{a}}$.
With regard to the role of hERG1 channels in apoptosis, this is still a controversial topic. Inhibition of hERG1 has been found to protect cells from apoptosis, as well as stimulating activity of the apoptosis executioner caspase-3. ${ }^{12,13,15}$ In our experimental conditions, hyperstimulation of the hERG1 channel did not induce apoptosis after arresting the cells in the G0/G1 phase. The lack of apoptosis in cells treated with NS1643 could be due to the drug-induced increase of the tumor suppressor p21 protein levels.

Our experiments revealed that the basal protein levels of p21 in untreated cells were barely detectable (Figure 6a). In contrast, in these cells basal level of cyclin E2 (Figure 4a) was highly expressed. This expression pattern is characteristic of proliferating cells.

Traditionally, an increase of p21 protein level can be linked to a cell cycle arrest as this protein inhibits cyclin E2 activity. ${ }^{45,46}$ However, in our experiments the hERG1 agonist-dependent augmentation of p21 protein level occurred only many hours after that cyclin E2 disappeared. Therefore, it is unlikely that the main function of p21 in the hERG1 agonisttreated cells would be to inhibit cyclin E2 activity.

Nevertheless, it has been also shown that elevation of p21 protein can protect against apoptosis. ${ }^{47-49}$ Our data confirm 
this hypothesis as high expression of p21 coincides with lack of apoptosis in NS1643-treated cells.

Interestingly, increase of p21 and p16 ${ }^{\mathrm{INK} 4 \mathrm{a}}$ are considered strong markers for cellular senescence; ${ }^{30,31,50-52}$ a distinctive cellular phenotype that is characterized by an irreversible arrest of the cell cycle. ${ }^{53,54}$ Accordingly, our attempts to rescue the effect of NS1643 on cell proliferation failed as no increase in growth rate was measured after removal of the drug. This suggests that the effect of NS1643 on cell proliferation was irreversible. In addition, we also detected a significant increase in the senescence marker $\beta$-galactosidase activity in cells treated with NS1643. In summary, the NS1643-dependent augmentation of $\mathrm{p} 21, \mathrm{p} 16^{\mathrm{INK} 4 \mathrm{a}}$ and $\beta$ galactosidase activities, in combination with irreversible arrest of the cell cycle in G0/G1 phase suggest that hyperstimulation of the hERG1 potassium channel can lead to activation of a senescence program.

It is clear that in almost all the forms of cancer, mechanisms promoting growth arrest including apoptosis or differentiation are inhibited. Although it is not yet well understood what roles senescent cells have in an organism, it has been proposed that this cellular phenotype can protect from tumor progression by limiting cancer cell proliferation. ${ }^{55,56}$ In addition, it is known that relapsing tumors can activate an inflammatory response that stimulates the immune system to remove senescent cells. ${ }^{57,58}$ Furthermore, senescent cells are more susceptible to the effects of chemotherapies. ${ }^{59}$ Therefore, stimulating hERG1 channel activity could be preparatory for more efficacious effects of an activated immune system and/ or antiproliferative drugs.

\begin{abstract}
Materials and Methods
Cell lines. Human mammary gland adenocarcinoma SKBR3 and MDA-MB-231 cells were a generous gift from Dr. Ajay Rana (Loyola University Chicago, IL, USA). SKBr3 cells were cultured in RPMI-1640 medium. MDA-MB-231 were cultured in L-15 medium. Both culturing media had 10\% fetal bovine serum. Chinese hamster ovary (CHO) cells were purchased from ATCC and grown in Dulbecco's modified Eagle's medium (high glucose) with $10 \%$ fetal bovine serum. All cell culture media included antibiotics (penicillin 100 and $100 \mu / \mathrm{ml}$ streptomycin).

Drugs: hERG1 agonists NS1643 and PD118057 were purchased, respectively from Alomone Labs (Jerusalem, Israel) and Tocris bioscience (Bristol, UK).
\end{abstract}

Western blot analysis. After treatment with hERG1 agonist as needed, cells were harvested by trypsinization with $0.25 \%$ Trypsin-EDTA, washed in PBS, and lysed with cold radioimmuniprecipitation assay (RIPA) buffer containing $50 \mathrm{~mm}$ Tris $\mathrm{HCl}$ (pH 8.0), $150 \mathrm{~mm} \mathrm{NaCl}, 1 \%$ Tergitol (Sigma-Aldrich, St. Louis, MO, USA ), 0.5\% Na-deoxycholate, $0.1 \%$ SDS, $1 \mathrm{~mm}$ phenylmethylsulfonyl fluoride, $1 \mathrm{~mm} \mathrm{NaF}, 1 \mathrm{~mm}$ $\mathrm{Na} 3 \mathrm{VO}$, and $1 \times$ Protease Inhibitor Cocktail (Sigma-Aldrich). Protein concentration was determined via BCA assay (Thermo Scientific). Laemmli buffer $4 \times$ was added to the protein samples, which were then heated at $95^{\circ} \mathrm{C}$ for $5 \mathrm{~min}$. The samples $(32 \mu \mathrm{g})$ were subjected to SDS-polyacrylamide gel electrophoresis on precast 4$15 \%$ gradient mini-gels (Bio-Rad, Hercules, CA, USA) and transferred onto a nitrocellulose membrane. Membranes were blocked in $5 \%$ non-fat milk in mixture of Tris-Buffered Saline (Sigma-Aldrich) containing 0.1\% Tween 20 (Sigma-Aldrich) (TBST) and washed in TBST before overnight incubation at $4{ }^{\circ} \mathrm{C}$ with primary cell cycle antibodies diluted 1:1000 ( $\mathrm{p} 16^{\mathrm{INK} 4 a}$ dilution was 1:500) in $3 \%$ bovine serum albumin in TBST. Then, the membrane was washed with TBST and incubated with the appropriate secondary antibody $(1: 2000)$ for $1 \mathrm{~h}$ at room temperature. All antibodies were purchased from Cell Signaling Technology Inc. (Boston, MA, USA) with the exception of the $11^{\text {INK4a }}$ antibody which was purchased from Abgent (San Diego, CA, USA). Membranes were washed with TBST and visualized using Super Signal West Pico Chemiluminescent Substrate (Thermo Scientific, Pittsburgh, PA, USA).
Electrophysiology. Whole-cell hERG currents were detected from cells voltage-clamped through gramicidin-perforated patches as previously described in Gentile et al. ${ }^{60}$

Cell proliferation assay. Cells were plated in estrogen-free medium and allowed to attach overnight before treatment with NS1643, refreshing the treatment every $24 \mathrm{~h}$ as needed. After the indicated time points, cells were trypsinized, washed with PBS, resuspended and stained for 1 min with 0.4\% Trypan Blue (GibCo/Life Technologies; Grand Island, NY, USA). Viable and dead cells were counted using a hemocytometer and cell counter (Countess; Invitrogen).

Cell cycle analysis. Control and treated cells were harvested using $0.25 \%$ Trypsin-EDTA, centrifuged $(300 \mathrm{~g})$, and washed once with cold PBS. The pellet was resuspended in ice cold $70 \%$ ethanol and stored at $-20^{\circ} \mathrm{C}$. Once all samples were collected, cells were centrifuged and resuspended in cold PBS. One million cells were counted, collected and centrifuged. Samples were incubated with RNase A (Promega, Madison, WI, USA; final concentration $=0.5 \mu \mathrm{g} / \mathrm{ml}$ ) and propidium iodide (Sigma-Aldrich; $(50 \mu \mathrm{g} / \mathrm{ml})$ for $2 \mathrm{~h}$ at $4^{\circ} \mathrm{C}$ before analysis with a flow cytometer and FlowJo software (Tree Star Inc.; Ashland, OR, USA).

AnnexinV assay. Cells were assayed for apoptosis using an Alexa Fluor 488 annexin V/Dead Cell Apoptosis Kit (Invitrogen) according to the manufacturer's instructions. In brief, cells were treated at the indicated time points, harvested with trypsin, resuspended in binding buffer (50 mM HEPES, $700 \mathrm{~mm} \mathrm{NaCl}, 12.5 \mathrm{~mm}$ $\left.\mathrm{CaCl}_{2}, \mathrm{pH} 7.4\right)$, and stained with both propidium iodide (1 mg/ml) and annexinV. After $15 \mathrm{~min}$ of incubation, cell suspensions were analysed with a flow cytometer. Data were analysed using FlowJo software (Tree Star, Inc.).

Senescence-associated acidic $\beta$-galactosidase staining. A senescence $\beta$-Galactosidase Staining Kit was purchased from Cell Signaling Technology Inc.(no. 9860) and employed as suggested by manufacturer's instructions.

\section{Conflict of Interest}

The authors declare no conflict of interest.

Acknowledgements. We would like to express our gratitude to Drs. Kenneth Byron and Bruce Cuevas, Clodia Osipo (Loyola University Chicago), David Armstrong (National Institute of Environmental Health Sciences/NIEHS/NIH), Norman Sharpless (University of North Carolina) for their valuable advices. We also thank Patricia Simms (Loyola University Chicago) for her excellent technical assistance.

1. Sanguinetti MC, Tristani-Firouzi M. hERG potassium channels and cardiac arrhythmia. Nature 2006; 440: 463-469.

2. Vandenberg JI, Perry MD, Perrin MJ, Mann SA, Ke Y, Hill AP et al. hERG K ( + ) channels: structure, function, and clinical significance. Physiol Rev 2012; 92: 1393-1478.

3. Arcangeli A, Rosati B, Crociani O, Cherubini A, Fontana L, Passani B et al. Modulation of HERG current and herg gene expression during retinoic acid treatment of human neuroblastoma cells: potentiating effects of BDNF. J Neurobiol 1999; 40: 214-225.

4. Cherubini A, Taddei GL, Crociani O, Paglierani M, Buccoliero AM, Fontana L et al. HERG potassium channels are more frequently expressed in human endometrial cancer as compared to non-cancerous endometrium. Br J Cancer 2000; 83: 1722-1729.

5. Hofmann G, Bernabei PA, Crociani O, Cherubini A, Guasti L, Pillozzi S et al. HERG K+ channels activation during beta(1) integrin-mediated adhesion to fibronectin induces an upregulation of alpha(v)beta(3) integrin in the preosteoclastic leukemia cell line FLG 29.1. J Biol Chem 2001; 276: 4923-4931.

6. Schonherr R, Rosati B, Hehl S, Rao VG, Arcangeli A, Olivotto M et al. Functional role of the slow activation property of ERG K + channels. Eur J Neurosci 1999; 11: 753-760.

7. Arcangeli A. Expression and role of hERG channels in cancer cells. Novartis Found Symp 2005; 266: 225-232; discussion 232-224.

8. Bianchi L, Wible B, Arcangeli A, Taglialatela M, Morra F, Castaldo P et al. herg encodes a $\mathrm{K}+$ current highly conserved in tumors of different histogenesis: a selective advantage for cancer cells? Cancer Res 1998; 58: 815-822.

9. Arcangeli A, Rosati B, Cherubini A, Crociani O, Fontana L, Ziller C et al. HERG- and IRKlike inward rectifier currents are sequentially expressed during neuronal development of neural crest cells and their derivatives. Eur J Neurosci 1997; 9: 2596-2604. 
10. Crociani O, Cherubini A, Piccini E, Polvani S, Costa L, Fontana L et al. erg gene(s) expression during development of the nervous and muscular system of quail embryos. Mech Dev 2000; 95: 239-243.

11. Crociani O, Guasti L, Balzi M, Becchetti A, Wanke E, Olivotto M et al. Cell cycle-dependent expression of HERG1 and HERG1B isoforms in tumor cells. J Biol Chem 2003; 278 : 2947-2955

12. Smith GA, Tsui HW, Newell EW, Jiang X, Zhu XP, Tsui FW et al. Functional up-regulation of HERG K+ channels in neoplastic hematopoietic cells. J Biol Chem 2002; 277: 18528-18534.

13. Pillozzi S, Brizzi MF, Balzi M, Crociani O, Cherubini A, Guasti L et al. HERG potassium channels are constitutively expressed in primary human acute myeloid leukemias and regulate cell proliferation of normal and leukemic hemopoietic progenitors. Leukemia 2002; 16: $1791-1798$

14. Jehle J, Schweizer PA, Katus HA, Thomas D. Novel roles for hERG $K(+)$ channels in cell proliferation and apoptosis. Cell Death Dis 2011; 2: e193.

15. Wang H, Zhang Y, Cao L, Han H, Wang J, Yang B et al. HERG K + channel, a regulator of tumor cell apoptosis and proliferation. Cancer Res 2002; 62: 4843-4848.

16. Diness TG, Yeh YH, Qi XY, Chartier D, Tsuji Y, Hansen RS et al. Antiarrhythmic properties of a rapid delayed-rectifier current activator in rabbit models of acquired long QT syndrome. Cardiovasc Res 2008; 79: 61-69.

17. Kang J, Chen XL, Wang H, Ji J, Cheng $\mathrm{H}$, Incardona J et al. Discovery of a small molecule activator of the human ether-a-go-go-related gene (HERG) cardiac $\mathrm{K}+$ channel. $\mathrm{Mol}$ Pharmacol 2005; 67: 827-836.

18. Zhou J, Augelli-Szafran CE, Bradley JA, Chen X, Koci BJ, Volberg WA et al. Novel potent human ether-a-go-go-related gene ( $h E R G$ ) potassium channel enhancers and their in vitro antiarrhythmic activity. Mol Pharmacol 2005; 68: 876-884.

19. Hansen RS, Diness TG, Christ T, Demnitz J, Ravens U, Olesen SP et al. Activation of human ether-a-go-go-related gene potassium channels by the diphenylurea 1,3-bis-(2hydroxy-5-trifluoromethyl-phenyl)-urea (NS1643). Mol Pharmacol 2006; 69: 266-277.

20. Hansen RS, Olesen SP, Ronn LC, Grunnet M. In vivo effects of the IKr agonist NS3623 on cardiac electrophysiology of the guinea pig. J Cardiovasc Pharmacol 2008; 52: 35-41.

21. Su Z, Limberis J, Souers A, Kym P, Mikhail A, Houseman K et al. Electrophysiologic characterization of a novel hERG channel activator. Biochem Pharmacol 2009; 77 1383-1390.

22. Szabo G, Farkas V, Grunnet M, Mohacsi A, Nanasi PP. Enhanced repolarization capacity: new potential antiarrhythmic strategy based on HERG channel activation. Curr Med Chem 2011; 18: 3607-3621.

23. Casis O, Olesen SP, Sanguinetti MC. Mechanism of action of a novel human ether-a-go go-related gene channel activator. Mol Pharmacol 2006; 69: 658-665.

24. Shao XD, Wu KC, Guo XZ, Xie MJ, Zhang J, Fan DM. Expression and significance of HERG protein in gastric cancer. Cancer Biol Ther 2008; 7: 45-50.

25. Le XF, Marcelli M, McWatters A, Nan B, Mills GB, O'Brian CA et al. Heregulin-induced apoptosis is mediated by down-regulation of $\mathrm{Bcl}-2$ and activation of caspase-7 and is potentiated by impairment of protein kinase C alpha activity. Oncogene 2001; 20: 8258-8269.

26. Yam CH, Fung TK, Poon RY. Cyclin A in cell cycle control and cancer. Cell Mol Life Sci 2002; 59: 1317-1326.

27. Nurse P. Wee beasties. Nature 2004; 432: 557 .

28. Nowak SJ, Corces VG. Phosphorylation of histone H3: a balancing act between chromosome condensation and transcriptional activation. Trends Genet 2004; 20: 214-220.

29. Dimri GP, Lee X, Basile G, Acosta M, Scott G, Roskelley C et al. A biomarker that identifies senescent human cells in culture and in aging skin in vivo. Proc Natl Acad Sci USA 1995 92: 9363-9367.

30. Kim WY, Sharpless NE. The regulation of INK4/ARF in cancer and aging. Cell 2006; 127: 265-275.

31. Kong $\mathrm{Y}$, Cui $\mathrm{H}$, Ramkumar $\mathrm{C}$, Zhang $\mathrm{H}$. Regulation of senescence in cancer and aging J Aging Res 2011; 2011: 963172.

32. Lehen'kyi V, Shapovalov G, Skryma R, Prevarskaya N. Ion channnels and transporters in cancer. 5. Ion channels in control of cancer and cell apoptosis. Am J Physiol Cell Physiol 2011; 301: C1281-C1289.

33. Arcangeli A, Yuan JX. American Journal of Physiology-Cell Physiology theme: ion channels and transporters in cancer. Am J Physiol Cell Physiol 2011; 301: C253-C254.

34. Becchetti $A$. Ion channels and transporters in cancer. 1. Ion channels and cell proliferation in cancer. Am J Physiol Cell Physiol 2011; 301: C255-C265.

35. Felipe A, Vicente R, Villalonga N, Roura-Ferrer M, Martinez-Marmol R, Sole $L$ et al. Potassium channels: new targets in cancer therapy. Cancer Detect Prev 2006; 30 375-385
36. Pardo LA, Contreras-Jurado C, Zientkowska M, Alves F, Stuhmer W. Role of voltage-gated potassium channels in cancer. J Membr Biol 2005; 205: 115-124

37. Sundelacruz S, Levin M, Kaplan DL. Role of membrane potential in the regulation of cell proliferation and differentiation. Stem Cell Rev 2009; 5: 231-246.

38. Bordey A, Sontheimer $\mathrm{H}$. Electrophysiological properties of human astrocytic tumor cells In situ: enigma of spiking glial cells. J Neurophysiol 1998; 79: 2782-2793.

39. Sherr CJ. G1 phase progression: cycling on cue. Cell 1994; 79: 551-555.

40. Hwang HC, Clurman BE. Cyclin E in normal and neoplastic cell cycles. Oncogene 2005; 24: 2776-2786.

41. Takahashi $Y$, Rayman JB, Dynlacht BD. Analysis of promoter binding by the E2F and pRB families in vivo: distinct E2F proteins mediate activation and repression. Genes Dev 2000; 14: 804-816.

42. Kothapalli D, Stewart SA, Smyth EM, Azonobi I, Pure E, Assoian RK. Prostacylin receptor activation inhibits proliferation of aortic smooth muscle cells by regulating cAMP response element-binding protein- and pocket protein-dependent cyclin a gene expression. $\mathrm{Mol}$ Pharmacol 2003; 64: 249-258.

43. Fang $X$, Jin $X, X u H J$, Liu L, Peng HQ, Hogg $D$ et al. Expression of $p 16$ induces transcriptional downregulation of the RB gene. Oncogene 1998; 16: 1-8.

44. Chien WW, Domenech C, Catallo R, Kaddar T, Magaud JP, Salles G et al. Cyclindependent kinase 1 expression is inhibited by $\mathrm{p} 16(\mathrm{INK} 4 \mathrm{a}$ ) at the post-transcriptional level through the microRNA pathway. Oncogene 2011; 30: 1880-1891.

45. Abbas T, Dutta A.. p21 in cancer: intricate networks and multiple activities. Nat Rev Cance 2009; 9: 400-414.

46. Gartel AL, Radhakrishnan SK. Lost in transcription: p21 repression, mechanisms, and consequences. Cancer Res 2005; 65: 3980-3985.

47. Janicke RU, Sohn D, Essmann F, Schulze-Osthoff K. The multiple battles fought by antiapoptotic p21. Cell Cycle 2007; 6: 407-413.

48. Wang YA, Elson A, Leder $P$. Loss of $p 21$ increases sensitivity to ionizing radiation and delays the onset of lymphoma in atm-deficient mice. Proc Natl Acad Sci USA 1997; 94: 14590-14595.

49. Gartel AL, Tyner AL. The role of the cyclin-dependent kinase inhibitor p21 in apoptosis. Mol Cancer Ther 2002; 1: 639-649.

50. Roninson IB. Oncogenic functions of tumor suppressor p21(Waf1/Cip1/Sdi1): association with cell senescence and tumor-promoting activities of stromal fibroblasts. Cancer Lett 2002; 179: 1-14.

51. Black DM. Characterization of a multi-tissue tumor suppressor and senescence gene. Br J Cancer 1999; 80(Suppl 1): 42-45.

52. Tsygankov D, Liu Y, Sanoff HK, Sharpless NE, Elston TC. A quantitative model for agedependent expression of the p16INK4a tumor suppressor. Proc Natl Acad Sci USA 2009; 106: 16562-16567.

53. Provinciali M, Cardelli M, Marchegiani F, Pierpaoli E. Impact of cellular senescence in aging and cancer. Curr Pharm Des 2013; 19: 1699-1709.

54. Campisi J. Cancer, aging and cellular senescence. In Vivo 2000; 14: 183-188.

55. Sugimoto M, Takahashi A, Hara E. [Tumor suppression by cellular senescence: molecular link between aging and cancer]. Tanpakushitsu Kakusan Koso 2006; 51: 10-17.

56. Garkavtsev I, Hull C, Riabowol K. Molecular aspects of the relationship between cancer and aging: tumor suppressor activity during cellular senescence. Exp Gerontol 1998; 33: 81-94

57. Hoenicke L, Zender L. Immune surveillance of senescent cells-biological significance in cancer- and non-cancer pathologies. Carcinogenesis 33: 1123-1126.

58. Xue W, Zender L, Miething C, Dickins RA, Hernando E, Krizhanovsky V et al. Senescence and tumor clearance is triggered by p53 restoration in murine liver carcinomas. Nature 2007; 445: 656-660.

59. Lafferty-Whyte K, Bilsland A, Cairney CJ, Hanley L, Jamieson NB, Zaffaroni N et al. Scoring of senescence signalling in multiple human tumor gene expression datasets, identification of a correlation between senescence score and drug toxicity in the $\mathrm{NCl60}$ panel and a pro-inflammatory signature correlating with survival advantage in peritoneal mesothelioma. BMC Genomics 2010; 11: 532.

60. Gentile S, Darden T, Erxleben C, Romeo C, Russo A, Martin N et al. Rac GTPase signaling through the PP5 protein phosphatase. Proc Natl Acad Sci USA 2006; 103: 5202-5206.

c)(-) Cell Death and Disease is an open-access journal published by Nature Publishing Group. This work is licensed under a Creative Commons Attribution-NonCommercialShareAlike 3.0 Unported License. To view a copy of this license, visit http://creativecommons.org/licenses/by-nc-sa/3.0/ 